\title{
STUDY THE EFFECT OF MYCOPLASMA CONTAMINATION OF EGGS USED IN VIRUS TITRATION AND EFFICACY OF SOME LIVE ATTENUATED POULTRY VIRAL VACCINES
}

\author{
MARWA FATHY ${ }^{1}$, MOUNIR M EL-SAFTY ${ }^{2}$, JAKEEN K EL-JAKEE ${ }^{3}$, HOWAIDA I ABD-ALLA ${ }^{4 *}$, HALA MAHMOUD $^{1}$
}

${ }^{1}$ Department of Bacterial Sterility, Central Laboratory for Evaluation of Veterinary Biologics, Abbasia, Cairo, Egypt. ${ }^{2}$ Department of Quality Control of SPF Eggs, Central Laboratory for Evaluation of Veterinary Biologics, Abbasia, Cairo, Egypt. ${ }^{3}$ Department of Microbiology, Faculty of Veterinary Medicine, Cairo University, Giza, Egypt. ${ }^{4}$ Department of Chemistry of Natural Compounds, National Research Centre, 12622 Dokki, Giza, Egypt. Email: howaida_nrc@yahoo.com

Received: 28 August 2016, Revised and Accepted: 28 September 2016

\section{ABSTRACT}

Objective: The study of Mycoplasma gallisepticum (MG) infection is needed, not only to understand the disease process but also to understand the interference with the evaluation of some live viral poultry vaccines. This study aims to investigate the titration and potency of some live attenuated poultry viral vaccines; Newcastle disease, infectious bronchitis, infectious bursal disease, and Reo in both specific pathogen-free (SPF) embryonated chicken eggs (ECEs) and chickens.

Methods: Titration of live attenuated viral poultry vaccines in ECEs was carried out by dividing the inoculated eggs into four groups; the pre-, simultaneously-, post-, and non-MG contaminated. MG effect on the potency test was carried out using seventeen groups of SPF chickens (25 chicken/ group) placed into separate isolators. Each live attenuated viral poultry vaccine was inoculated into 4 groups.

Results: The highest titer of these vaccines that appeared in MG pre- contaminated ECEs were $10^{11}, 10^{7.5}, 10^{7.9}$, and $10^{7.5}$, respectively. The lowest vaccine titers that appeared in non-MG contaminated ECEs were $10^{8}, 10^{6}, 10^{6.8}$, and $10^{6}$, respectively. Although the potency of these previous vaccines indicated that the highest antibodies titer that appeared in MG pre-infected vaccinated chickens were $7.5 \log _{2}$, 36 enzyme-linked immunosorbent assay unit (EU), and $42 \mathrm{EU}$, respectively; the lowest antibodies titer that appeared in non-MG infected vaccinated chickens were $6.5 \log _{2}, 12 \mathrm{EU}, 17 \mathrm{EU}$, and $10 \mathrm{EU}$, respectively.

Conclusion: The present study findings underline the importance of using Mycoplasma -free eggs or chicken for the production of virus vaccines.

Keywords: Mycoplasma gallisepticum, Newcastle disease virus, Infectious bronchitis virus, Infectious bursal disease virus, Reo virus, Chicken, Specific pathogen-free eggs.

(c) 2017 The Authors. Published by Innovare Academic Sciences Pvt Ltd. This is an open access article under the CC BY license (http://creativecommons. org/licenses/by/4. 0/) DOI: http://dx.doi.org/10.22159/ajpcr.2017.v10i1.14930

\section{INTRODUCTION}

One of the most important mycoplasmas isolated from domestic avian species is Mycoplasma gallisepticum (MG) [1]. MG causes chronic respiratory disease of chickens and infectious sinusitis in turkeys, resulting in economic losses. It is transmitted through the egg and is well-known for its interactions with other infectious agents [1].

Mycoplasmas, particularly species of the genera Mycoplasma, are frequent contaminants of vaccine substrates, that is, continuous cell lines, and less frequently, animal-derived tissues and primary cell cultures [2]. Mycoplasma may affect the cell-mediated immune system by inducing either suppression or stimulation of $\mathrm{B}$ and $\mathrm{T}$ lymphocytes and inducing cytokines [3].

Newcastle disease (ND), infectious bronchitis (IB), infectious bursal disease (IBD), and Reovirus strains can be categorized as velogenic (highly virulent) and mesogenic (intermediate virulence) [4]. These diseases were reported as the most important viral diseases of poultry in the world including developing countries [5-7]. ND virus strains are spread rapidly between bird flocks so vaccination is necessary and is routinely performed using live-virus vaccines against ND virus (lentogenic strain LaSota), which is commonly produced using embryonated chicken eggs (ECEs) [4]. So that, mixed infections involving Mycoplasma, viruses, and bacteria are well-recognized in chickens. Synergism has been demonstrated between MG and the viruses of ND and IB [8]. Both MG and ND virus are able to successfully propagate in ECEs. The chicken embryo could represent a model system for the analysis of consecutive Mycoplasma synoviae (MS) -lentogenic-ND virus co-infection that may occur after ND virus infection (e.g., vaccination) of MS-infected host. Co-infections with MS and different avian viruses, concerning clinical signs, have been described by Kleven [1] and Landman and Feberwee [9]. Moreover, Mycoplasma hyorhinis always occurs worldwide as a co-infection with other swine pathogens, such as porcine reproductive and respiratory syndrome virus or porcine circovirus-2 [10].

Avian IB infection may precipitate latent Mycoplasma infection. Many studies [11,12] emphasize the importance of using Mycoplasmafree eggs for the production of virus vaccines. There was at least one hundred-fold increase in the multiplication of $M G$ in eggs simultaneously or previously infected with avian IB virus (IBV) made by inoculation of eggs in the allantoic sacs of 10-day embryonated hen' eggs [11].

When mildly virulent virus strains infect birds, which have already been infected with Mycoplasma, interactions between the host, Mycoplasma cells, and the virus may result in effects that differ from those which are expected after single pathogen infection [13]. Thus, severe inflammatory reactions and synergistic pathogen interactions can occur after vaccinations with live virus vaccines [13]

The current study aimed to clarify the effect of MG contamination in specific pathogen-free (SPF) eggs or infected chickens on virus titration and efficacy of some live attenuated viral poultry vaccines. 


\section{METHODS}

\section{SPF eggs}

Fertile SPF eggs were obtained from the national project for production of SPF eggs (Nile SPF eggs), Koom Oshiem, Fayoum, Egypt. Furthermore, they were hatched in the Central Laboratory for Evaluation of Veterinary Biologics (CLEVB), Cairo, Egypt.

\section{Chickens}

Four hundred forty-five of 14 days SPF chickens were obtained from the national project for production of SPF eggs (Nile SPF eggs), Koom Oshiem, Fayoum, Egypt.

\section{MG strain and its growth media}

MG strain was obtained from Animal Health Institute in Dokki, Mycoplasma department. This strain was propagated according to Naylor et al. [14]. The number of colony forming units (CFU) was determined by the standard procedures of Rodwell and Whitcomb [15] to obtain $10^{6} \mathrm{CFU}$ of MG strain to be inoculated in different groups of ECEs and chickens.

\section{MG antigen and antiserum}

MG colored antigens and chicken anti-MG sera were used for serum plate agglutination test (SPA). They were kindly obtained from Mycoplasma Department, Animal Health Research Institute, Dokki - Giza, Egypt.

\section{Live attenuated viral poultry vaccines}

Four types of live attenuated viral poultry vaccines (ND, IB, IBD, and Reo virus vaccines) were obtained from CLEVB. The vaccines were kept at refrigerator $\left(4-8^{\circ} \mathrm{C}\right)$ till use.

\section{Virus strains}

Newcastle disease virus (NDV) strain genotype 7 accession No.KM288609, standard local viral strains of IB, IBD and Reo were obtained from Viral Strain Bank of CLEVB that used for challenge tests.

\section{Experimental design}

Titration of $N D, I B, I B D$, and reo live attenuated viral poultry vaccines in ECES

The titration of ND vaccine

Ten-fold serial dilutions $\left(10^{-1}-10^{-12}\right)$ of the vaccine were prepared in sterile saline with antibiotic. Of each dilution, $0.2 \mathrm{ml}$ was inoculated in 20 eggs via allantoic cavityper egg (in 9- to 11-day-old embryonated SPF chicken eggs according to Senne [16]. The inoculated eggs of each dilution were divided into four groups (pre-, simultaneously-, post-, and non-MG contaminated) as follow:

Group A (pre-MG contaminated): Five eggs inoculated with $0.2 \mathrm{ml}$ of $5 \times 10^{6} \mathrm{CFU}$ of MG strain first at 7 -day-old in yolk sac (intra-yolk route). Yolk sac inoculation procedure followed the procedure reviewed by Senne [16] and then at 9-day-old inoculated with NDV via allantoic cavity.

Group B (simultaneously-MG contaminated): Five eggs inoculated simultaneously by $0.2 \mathrm{ml}$ of $5 \times 10^{6} \mathrm{CFU}$ of MG strain with the vaccine.

Group C (post-MG contaminated): Five eggs inoculated with $0.2 \mathrm{ml}$ of each dilution of NDV first at 9-day-old and then $0.2 \mathrm{ml}$ of $5 \times 10^{6} \mathrm{CFU}$ of MG strain via allantoic cavity.

Group D (non-MG contaminated): Five eggs per each dilution inoculated with $0.2 \mathrm{ml}$ of NDV at 9-day-old via allantoic cavity.

The inoculated eggs were incubated at $37^{\circ} \mathrm{C}$ with $60 \%$ humidity and candled daily for 6 days later. Dead embryos (within 24 hrs) were discarded and considered non-specific. Then, any dead embryos after these $24 \mathrm{hrs}$ were removed and kept in refrigerator at $4^{\circ} \mathrm{C}$ and recorded daily for calculation of the titer of the vaccine at the end of the sixth day and all remained eggs were put in refrigerator. Haemagglutination test (HI) was applied on the allantoic fluid of the inoculated eggs, and the positives were counted, and the titer was calculated [17].
The titration of IB vaccine

All previous steps of the previous experiment were applied with the exception that the vaccine of IB dilutions was from $10^{-1}$ to $10^{-8}$. In addition, the titer of vaccine was calculated according to criteria of embryo [17].

The titration of IBD and Reo vaccine

All previous steps used in the titration of IB vaccine were applied.

\section{MG effect on the potency test for the evaluation of live attenuated} viral poultry vaccines

Seventeen groups of SPF chickens (25 chicken/group) were placed into separate isolators. Each live attenuated viral poultry vaccine was inoculated into 4 groups as follows: Group 1 inoculated with MG at 14 days old SPF chickens $0.25 \mathrm{ml}$ intranasally (i.n.) and $0.25 \mathrm{ml}$ by subcutaneous (s.c.) route of $10^{6} \mathrm{CFU}$ of prepared MG then ND virus vaccine (NDVV) was inoculated. Group 2 inoculated with NDVV simultaneously with MG $\left(0.25 \mathrm{ml}\right.$ i.n. and $0.25 \mathrm{ml}$ s.c. route of $10^{6} \mathrm{CFU}$ of prepared MG. Group 3 inoculated with NDVV and then infected with MG $0.25 \mathrm{ml}$ i.n. and $0.25 \mathrm{ml}$ by s.c. route of $10^{6} \mathrm{CFU}$ of prepared MG 5 days post vaccination. Group 4 inoculated with NDVV. Groups 1-4 were inoculated with NDVV according to recommend manufactured dose and route of vaccine at 21-day-old. Groups (5-8), (9-12), and (13-16) were vaccinated with IB, IBD, and Reo VV, respectively, as mentioned before in Groups 1-4. Group 17 was kept as control non-infected unvaccinated group.

\section{MG re-isolation and identification}

\section{Re-isolation}

The re-isolation of MG was done by taken egg yolk samples from the contaminated ECEs (pre-, simultaneous- and post-contamination). Swabs were taken from the eyes, nostrils, and pharyngeal of infected chickens (pre-, simultaneous- and post-infection). The egg yolk samples and different swabs were dipped into pleuropneumonia-like organisms (PPLO) broth medium (Difco Laboratories) to enhance isolation of Mycoplasma [18]. The cultured broth was incubated at $37^{\circ} \mathrm{C}$ in $\mathrm{CO}_{2}$ incubator $\left(10 \% \mathrm{CO}_{2}\right)$ for $48-72$ hrs or until the color of the broth changed. After that loopful of the culture broth was placed on PPLO agar plate [19], incubate the plate at $37^{\circ} \mathrm{C}$ in $\mathrm{CO}_{2}$ incubator for 5-7 days. The plate was examined daily under stereo-zone microscope for identification of fried egg colonies specific to Mycoplasma.

\section{MG identification}

Egg yolk and blood samples [20] were collected randomly from contaminated ECEs and infected chickens in pre, simultaneously and post groups, then egg yolk and serum samples were prepared for SPA test to ensure the presence of MG.

\section{Egg yolk and blood samples collection and preparation}

The egg yolk and serum preparation were done according to Office International Des Epizooties (OIE) [21].

\section{Haemagglutination inhibition (HI) test}

It was applied for calculating the titer of ND virus in the collected allantoic fluid of all inoculated groups of ECEs according to OIE [21]. All serum samples from Groups 1-4 were collected for estimation of antibody titers against ND virus using HI test [22]. The test was performed according to the procedure of OIE (2002). In brief, twofold serial dilution of $25 \mu \mathrm{l}$ serum was made with phosphate-buffered saline (PBS) in V-bottomed microtiter plates (Nunc) up to $10^{\text {th }}$ well. $25 \mu \mathrm{l}$ of 4 hemagglutinating (HA) units of virus or antigen was added up to $11^{\text {th }}$ well. The plates were kept at room temperature for more than 30 minutes to facilitate antigen-antibody reaction. Then, $50 \mu \mathrm{l}$ of $1 \%(\mathrm{v} / \mathrm{v})$ chicken red blood cells (RBCs) suspension was added to each well. The $11^{\text {th }}$ well contains antigen and RBCs as the positive control, and the $12^{\text {th }}$ well contains only RBCs as the negative control. After gentle mixing, the RBCs were allowed to settle at room temperature for 40 minutes, and agglutination was assessed by tilting the plates. The samples showing peculiar central button shaped settling of RBCs were 
recorded as positive and maximum dilution of each sample causing $\mathrm{HI}$ was considered the end point, which was used to estimate the HI titer. The HI titer of each serum sample was expressed as reciprocal of the serum dilution.

\section{Enzyme-linked immunosorbent assay (ELISA)}

It was conducted as described by Jordan et al. [23]. IBV AB ELISA kit was used for estimation of antibodies titers against IBV in serum samples collected from Groups 5 to 8.

AB ELISA kit calculated the antibodies titer against IBD virus (IBDV) in serum samples collected from Groups 9 to 12 . While ReoV AB ELISA kit was used for estimation of antibodies titers against Reovirus in serum samples collected from Groups 13 to 16 .

\section{Challenge test}

At 28 days post-vaccination, the vaccinated and control groups were challenged then kept under observation for 10-14 days post-challenge.

Chicken groups vaccinated by ND vaccine were challenged intramuscularly with a local virulent strain of ND virus containing at least $10^{6}$ embryo lethal doses $\left(\mathrm{ELD}_{50}\right)$ /bird [24].

Chicken groups vaccinated by IB and IBDV vaccine were challenged with a standard virulent strain of the virus of IB (M41 type) and IBD $(52 / 70)$, respectively. Each bird received at least $10^{3.5} \mathrm{ELD}_{50}$ of challenge IBV virus intranasal. While each bird received at least $10^{3} \operatorname{ELD}_{50}$ of challenge IBDV virus by conjunctiva instillation.

Chicken groups vaccinated by Reo virus vaccine were challenged with a standard virulent strain of avian Reovirus strain S1133. Each bird received at least $10^{3.5} \mathrm{EID}_{50}$ of challenge Reovirus into the foot pad $0.1 \mathrm{ml} /$ chicken.

\section{RESULTS}

\section{Mycoplasma re-isolation from ECEs and chicken swabs}

All samples taken from egg yolk and swabs, from both contaminated eggs and infected chickens of pre-, simultaneous- and post-MG groups, were gave fried egg colonies, by examination under stereo-zone microscope. While samples obtained from non-MG contaminated and infected groups were not gave any colonies.

\section{Mycoplasma identification by SPA test}

All collected samples of egg yolk and serum samples from both contaminated eggs and infected chickens of pre-, simultaneous- and post-MG groups were gave clear agglutination by SPA test while there was any agglutination in samples obtained from non-MG contaminated and infected groups

Titration of live attenuated vaccines in SPF-ECEs among MG-infected groups

Table 1 indicated that the highest titer of ND virus by HA test, applied on allantoic fluid of ECEs, was appeared in Mycoplasma pre-contaminated group $\left(10^{11}\right)$.

The lowest titers were recorded in Mycoplasma non-infected group $\left(10^{8}\right)$. The highest titer of IBV was appeared in Mycoplasma precontaminated group $\left(10^{7.5}\right)$, whereas the lowest titers were recorded in IBV MG non-infected group $\left(10^{6}\right)$.

The highest titer of IBDV was appeared in Mycoplasma pre-contaminated group $\left(10^{7.9}\right)$, whereas the lowest titers were recorded in IBD inoculated without $\mathrm{MG}$ contamination group $\left(10^{6.8}\right)$.

Finally, the highest titer of Reo virus was appeared in Mycoplasma precontaminated group $\left(10^{7.5}\right)$, whereas the lowest titers were recorded in Reo virus inoculated without MG contamination group $\left(10^{6}\right)$. Fig. $1 \mathrm{a}$ shows normal embryos and Fig. 1b shows curling and dwarfism of inoculated embryos characteristic to IBV. Fig. 2a shows normal embryo liver and Fig. 2b shows yellowish-white discoloration of embryo liver indicated the characteristic lesion of IBDV. Fig. 3a shows normal embryo while Fig. 3 b shows strawberry like embryos due to Reo virus inoculation.

Table 2 indicatesthat the highest titer of ND antibodies by HI test at the 28 days post-inoculation was appeared in Mycoplasma pre-infected group (7.5 $\log _{2}$ ), whereas the lowest titers were recorded in NDV inoculated alone group $\left(6.5 \log _{2}\right)$. The protection percentage against NDV revealed that the Mycoplasma pre-infected, ND challenged group was more protected group $(100 \%)$ than simultaneously and post Mycoplasma infected group (95\%) and the non-infected ND challenged group recorded lowest protection percent (90\%). Fig. 4 illustrateds the postmortem lesions showed the presence of petechial hemorrhage all over mucous membranes of the proventriculus in challenged unvaccinated group that are characteristic to NDV. Fig. 5 represents SPF chickens showed nervous manifestations after challenged unvaccinated group with NDV.

The results in Table 3 recorded that the highest titer of IB antibodies by ELISA test on collected serum at the 28 days post inoculation of chickens was in Mycoplasma pre-infected group (36 ELISA unit [EU]) while the lowest titers were recorded in IB inoculated without MG-infected group (12 EU). The protection percentage against IBV revealing that the Mycoplasma pre-infected, IB challenged group was more protected group $(100 \%)$ than simultaneously and post Mycoplasma-infected group (95\%) and the non-infected IBV challenged group recorded lowest protection percent (90\%).

The highest titer of IBD antibodies by ELISA test on collected serum at the 28 days post inoculation was in Mycoplasma pre-infected group (42 EU) while the lowest titers were recorded in IBD inoculated without MG-infected group (17 EU). The protection percentage against IBDV revealed that all MG-infected IBD challenged groups showed higher protection percentage $(100 \%)$ than the MG noninfected IBD challenged group that recorded (90\%). The highest titer of Reo antibodies by ELISA test on collected serum at the 28 days post inoculation was in Mycoplasma pre-infected group (14 EU) while the lowest titers were recorded in Reo inoculated without MG-infected group (10 EU). The highest protection percentage against Reovirus was in Reo challenged MG (Pre- and simultaneously infected group (100\%) while the MG non-infected Reo challenged group was the lowest protected group (90\%). Fig. 6 have arrows refer to bronchioles containing caseous plugs in IBV challenged unvaccinated chicken which characteristics to IB disease. Fig. 7 shows SPF chicken have gasping of air in unvaccinated group challenged with IBV. Fig. 8a showskidneys of unvaccinated chicken affected by a severe urate diathesis due to challenge with IBDV while Fig. 8b shows enlarged
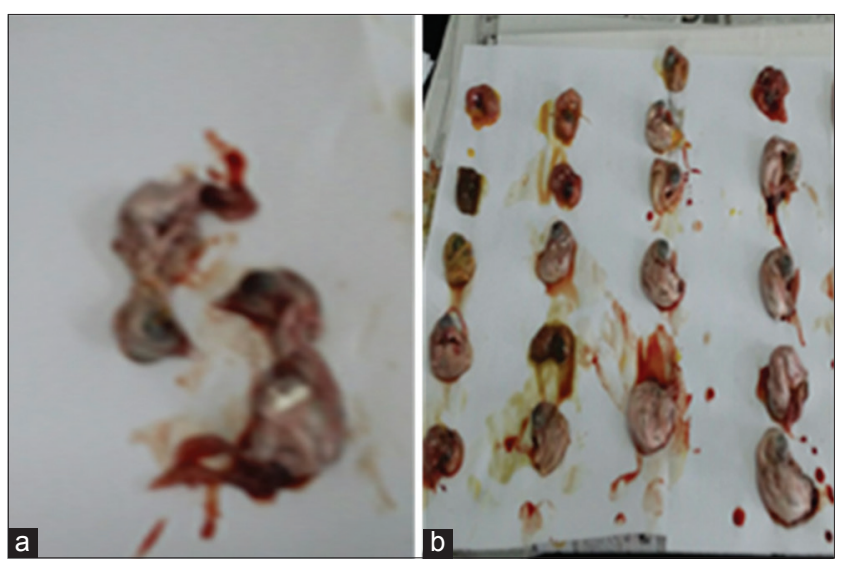

Fig. 1: (a) Normal embryos, (b) Curling and dwarfism of inoculated embryos characteristic to infectious bronchitis virus 
bursa of fabricius with yellowish peribursal oedema in unvaccinated chicken challenged with IBDV. Fig. 8c shows hemorrhages on thigh muscles in unvaccinated chicken challenged with IBDV. Fig. 9 of SPF chicken shows severe diarrhea in unvaccinated group challenged with IBDV. In Fig. 10, the red rings showed malabsorption syndrome (characteristics to Reo disease) in proventriculus of unvaccinated chicken challenged with Reo virus. Fig. 11 illustrates the SPF chicken showed limpness associated with tenosynovitis in challenged unvaccinated group with Reo virus.

\section{DISCUSSION}

The current study investigated the effect of MG contamination to fertile SPF eggs and chickens on the titration and potency of some live attenuated poultry viral vaccines (ND, IB, IBD and Reo virus) was carried out. ECEs are among the most useful and available

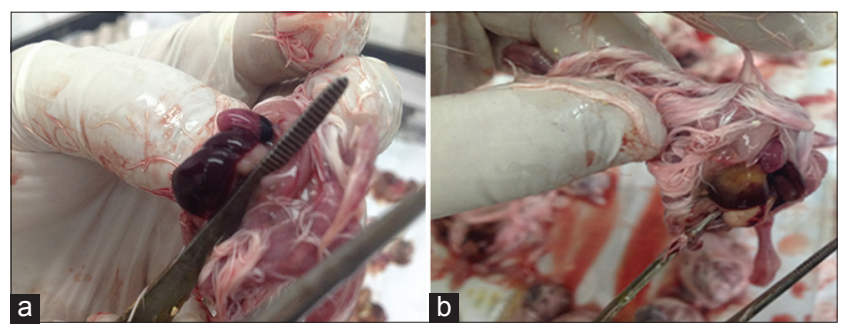

Fig. 2: (a) Normal embryo liver, (b) Yellowish-white discoloration of embryo liver indicated the characteristic lesion of infectious bursal disease virus

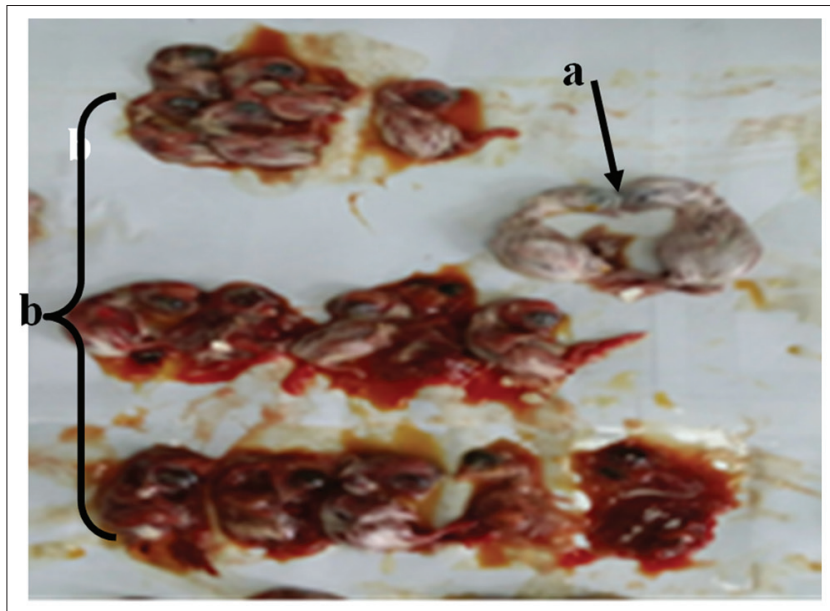

Fig. 3: (a) Normal embryo, (b) Strawberry like embryos due to Reo virus inoculation

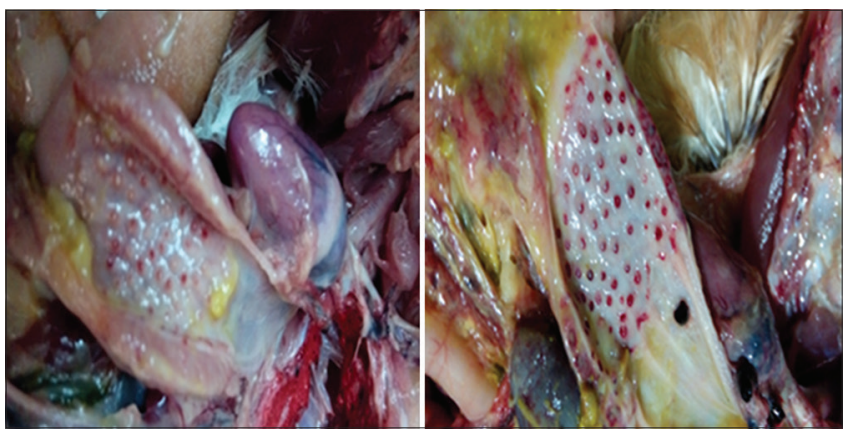

Fig. 4: Postmortem lesions showed the presence of petechial haemorrhage all over mucous membranes of the proventriculus in challenged unvaccinated group which are characteristic to Newcastle disease virus forms of living animal tissue for the isolation and identification of viruses, for titrating viruses, and for quantity cultivation in the production of viral vaccines [25]. Therefore, inoculated ECEs with MG in three ways, pre-, simultaneously- and post- of the inoculated vaccines were chosen, in the current study. It is clear that MG inoculations enhance the replication of viruses and increase their titers in ECEs. These results are supported with Bolha et al. [26] who reported that when mildly virulent virus strains infect birds

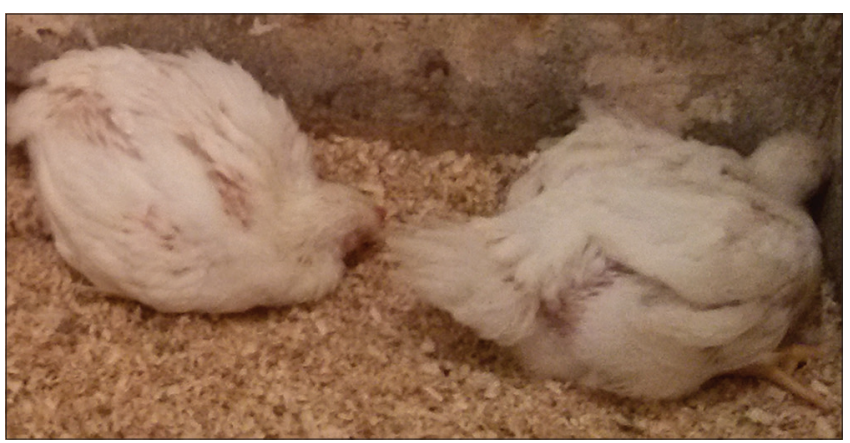

Fig. 5: Specific pathogen-free chickens showed nervous manifestations after challenged unvaccinated group with Newcastle disease virus

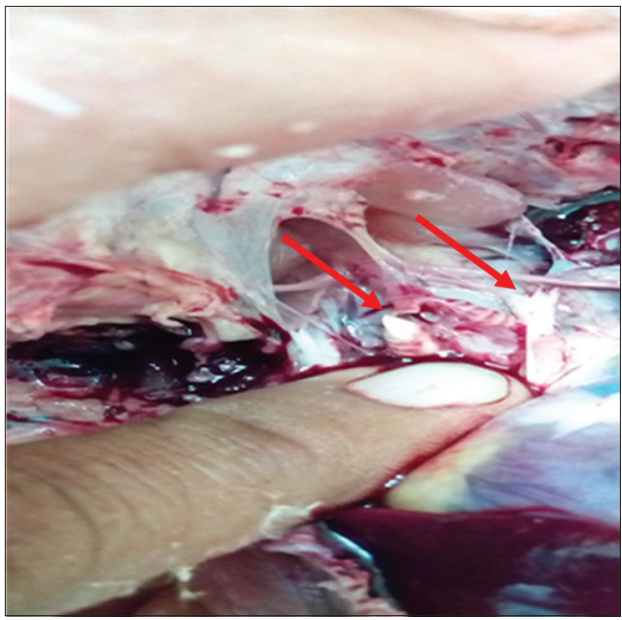

Fig. 6: Arrows refer to bronchioles containing caseous plugs in infectious bronchitis virus challenged unvaccinated chicken which characteristics to infectious bronchitis disease

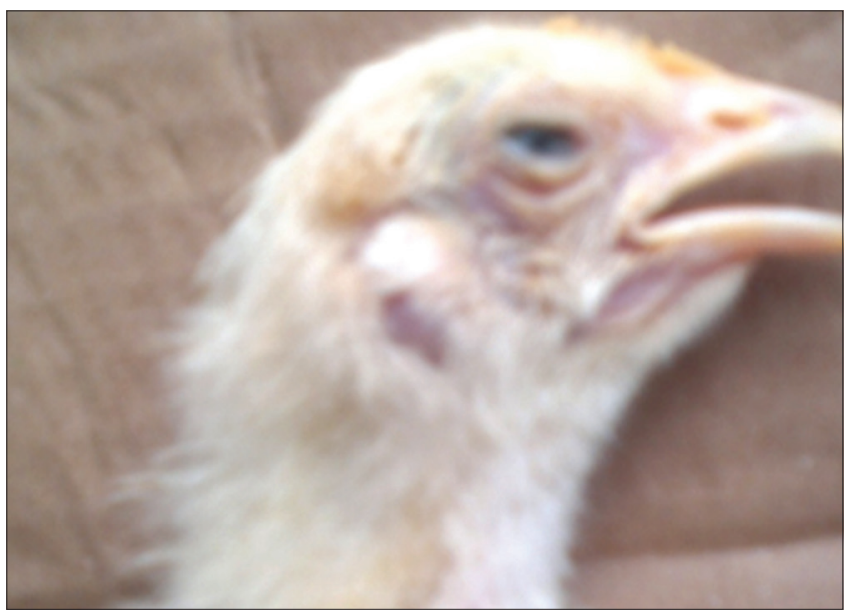

Fig. 7: Specific pathogen-free chicken show gasping of air in unvaccinated group challenged with infectious bronchitis virus 
that have already been infected with Mycoplasma, interactions between the host, Mycoplasma cells, and virus may result in effects that differ from those which are expected after single pathogen infection.

The present study depended on the fact that Mycoplasma can be transmitted vertically to eggs. MG seemed to play a role in increasing the titer of inoculated viruses (ND, IB, IBD, and Reo) in eggs that

Table 1: Titration of live attenuated vaccines in SPF ECEs

\begin{tabular}{lllll}
\hline Infected groups & \multicolumn{2}{l}{ Vaccine } & & \\
\cline { 2 - 5 } & ND & IB & IBD & Reo \\
\hline Pre-MG & $10^{11}$ & $10^{7.5}$ & $10^{7.9}$ & $10^{7.5}$ \\
Simultaneous-MG & $10^{9.5}$ & $10^{7}$ & $10^{7.2}$ & $10^{7}$ \\
Post-MG & $10^{10}$ & $10^{6.8}$ & $10^{7}$ & $10^{6.8}$ \\
Non-MG & $10^{8}$ & $10^{6}$ & $10^{6.8}$ & $10^{6}$ \\
\hline
\end{tabular}

SPF: Specific pathogen-free, ECEs: Embryonated chicken eggs, MG: Mycoplasma gallisepticum, IBD: Infectious bursal disease, IB: Infectious bronchitis might be due to changing the $\mathrm{pH}$ of the egg content by the metabolite products of Mycoplasma obtained from its multiplication inside the egg [12]. MG can multiply on the chorioallantoic or allantoic sac despite its inoculation intra-yolk [27]. The two routes of egg inoculation (intra yolk and intra allantoic) for inoculation of ECEs were used in the current study.

Mixed infections involving Mycoplasma, viruses, and bacteria are well recognized in chickens. Synergism has been demonstrated between MG and the viruses of ND and IB and Escherichia coli [8].

The current study results showed the highest titer of ND virus by HA test, applied on allantoic fluid of ECEs, was appeared in Mycoplasma pre-contaminated group while the lowest titers were recorded in ND inoculated without MG contamination group. Co-infections were more severe than single infections [28]. Both MG and ND virus can successfully propagate in ECEs. The chicken embryo could represent a model system for the analysis of consecutive MS-lentogenic ND virus co-infection that may occur after the virus infection (e.g., vaccination) as concluded by Bolha et al. [26].

Table 2: Antibody titers tested by HI test and protection percent among the vaccinated groups

\begin{tabular}{|c|c|c|c|c|c|c|}
\hline \multirow[t]{2}{*}{ Groups } & \multirow[t]{2}{*}{$14^{\text {th }} \mathrm{PV}$} & \multirow[t]{2}{*}{$21^{\text {th }} \mathrm{PV}$} & \multirow[t]{2}{*}{$28^{\text {th }} \mathbf{P V}$} & \multirow[t]{2}{*}{ Protection percent } & \multicolumn{2}{|l|}{ t-test } \\
\hline & & & & & Sig. (two-tailed) & SD \\
\hline G1 & $5.4 \log _{2}$ & $6.5 \log _{2}$ & $7.5 \log _{2}$ & 100 & 0.035 & 7.0000 \\
\hline G2 & $4.9 \log _{2}$ & $6.2 \log _{2}$ & $7.2 \log _{2}$ & 95 & 0.012 & 1.17898 \\
\hline G3 & $4.5 \log _{2}$ & $5.8 \log _{2}$ & $6.8 \log _{2}$ & 95 & 0.013 & 1.153256 \\
\hline G4 & $4.2 \log _{2}$ & $5.5 \log _{2}$ & $6.5 \log _{2}$ & 90 & 0.015 & 1.153256 \\
\hline
\end{tabular}

PV: Post-vaccination, G1: The infected with MG then vaccinated with Newcastle disease virus vaccine (NDVV), G2: The vaccinated with NDVV and simultaneously infected with MG, G3: The vaccinated with then infected with MG, G4: The vaccinated only with NDVV, Sig.: Significance (0.01-0.05), SD: Standard deviation, HI: Haemagglutination test, MG: Mycoplasma gallisepticum

Table 3: Antibody titers tested by ELISA and protection percent among the vaccinated groups

\begin{tabular}{|c|c|c|c|c|c|c|}
\hline \multirow[t]{2}{*}{ Groups } & \multirow[t]{2}{*}{$14^{\text {th }} P V$} & \multirow[t]{2}{*}{$21^{\text {th }} \mathrm{PV}$} & \multirow[t]{2}{*}{$28^{\text {th }} \mathrm{PV}$} & \multirow[t]{2}{*}{ Protection percent* } & \multicolumn{2}{|l|}{ t-test } \\
\hline & & & & & Sig. (two-tailed) & SD \\
\hline G5 & $25 \mathrm{EU}$ & $35 \mathrm{EU}$ & $36 \mathrm{EU}$ & 100 & 0.012 & 6.082763 \\
\hline G6 & $10 \mathrm{EU}$ & $15 \mathrm{EU}$ & $22 \mathrm{EU}$ & 95 & 0.046 & 6.027714 \\
\hline G7 & $8 \mathrm{EU}$ & $11 \mathrm{EU}$ & $14 \mathrm{EU}$ & 95 & 0.024 & 3.000000 \\
\hline G8 & $7 \mathrm{EU}$ & $10 \mathrm{EU}$ & $12 \mathrm{EU}$ & 90 & 0.022 & 2.516611 \\
\hline G9 & $18 \mathrm{EU}$ & $30 \mathrm{EU}$ & $42 \mathrm{EU}$ & 100 & 0.049 & 12.000000 \\
\hline G11 & $9 \mathrm{EU}$ & $16 \mathrm{EU}$ & $20 \mathrm{EU}$ & 100 & 0.043 & 5.567764 \\
\hline G12 & $7 \mathrm{EU}$ & $12 \mathrm{EU}$ & $17 \mathrm{EU}$ & 90 & 0.053 & 5.000000 \\
\hline G13 & $6 \mathrm{EU}$ & $11 \mathrm{EU}$ & $14 \mathrm{EU}$ & 100 & 0.047 & 4.041452 \\
\hline G14 & $6 \mathrm{EU}$ & $10 \mathrm{EU}$ & $12 \mathrm{EU}$ & 100 & 0.034 & 3.055050 \\
\hline G15 & $6 \mathrm{EU}$ & $10 \mathrm{EU}$ & $11 \mathrm{EU}$ & 95 & 0.028 & 2.645751 \\
\hline G16 & $4 \mathrm{EU}$ & $8 \mathrm{EU}$ & $10 \mathrm{EU}$ & 90 & 0.053 & 3.055050 \\
\hline
\end{tabular}

PV: Post-vaccination, G5-8: Vaccinated with IB VV, G9-12: Vaccinated with IBD VV, G13-16: 20 Vaccinated with Reo VV, G5-16: They were vaccinated with virus vaccine as mentioned before in Groups 1-4; *: $6^{\text {th }}$ days post challenge, EU: ELISA unit, Sig.: Significance (0.01-0.05), SD: Standard deviation, ELIZA: Enzyme-linked immunosorbent assay
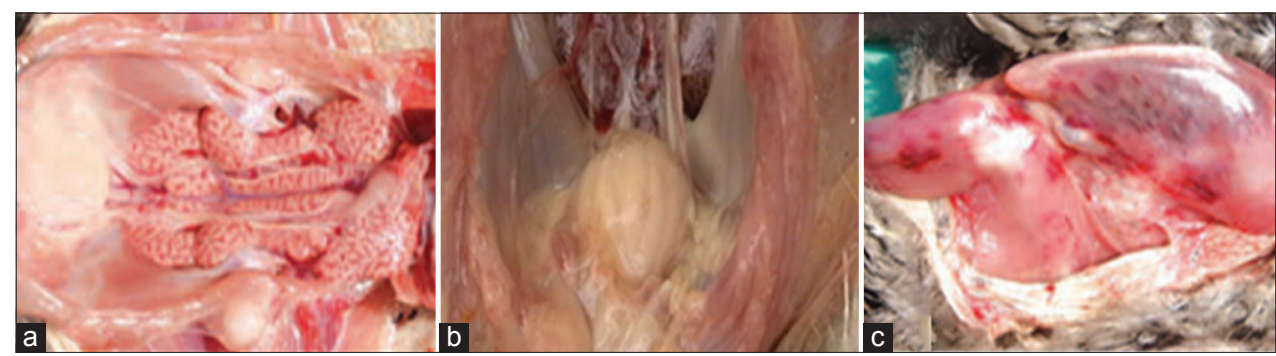

Fig. 8: (a) Kidneys of unvaccinated chicken affected by a severe urate diathesis due to challenge with infectious bursal disease virus (IBDV), (b) enlarged bursa of fabricius with yellowish peribursal oedema in unvaccinated chicken challenged with IBDV, (c) hemorrhages on thigh muscles in unvaccinated chicken challenged with infectious bursal disease virus 


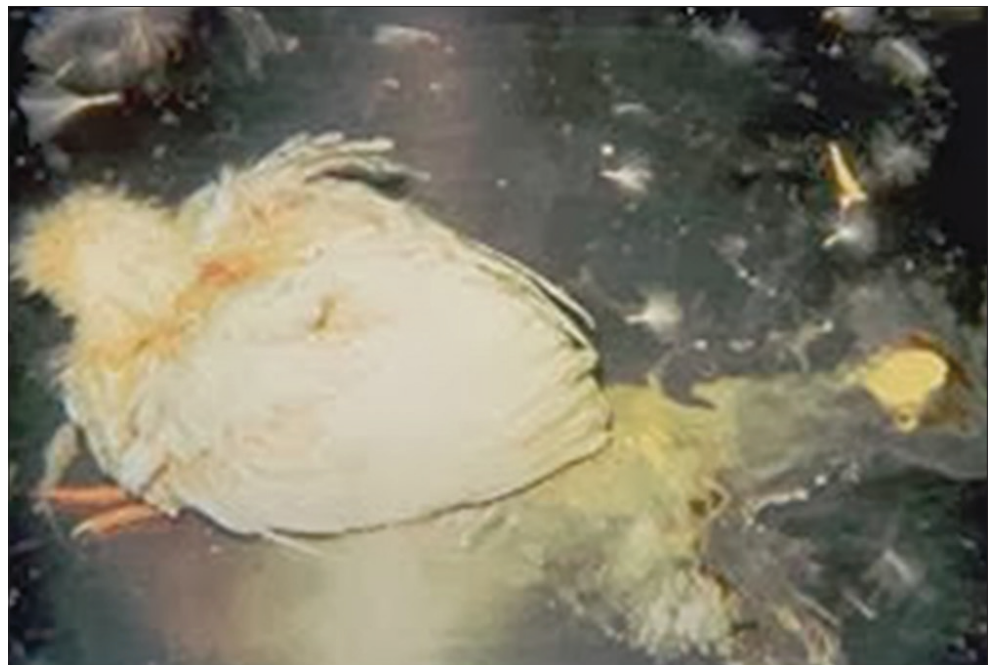

Fig. 9: Specific pathogen-free chicken showed severe diarrhea in unvaccinated group challenged with infectious bursal disease virus

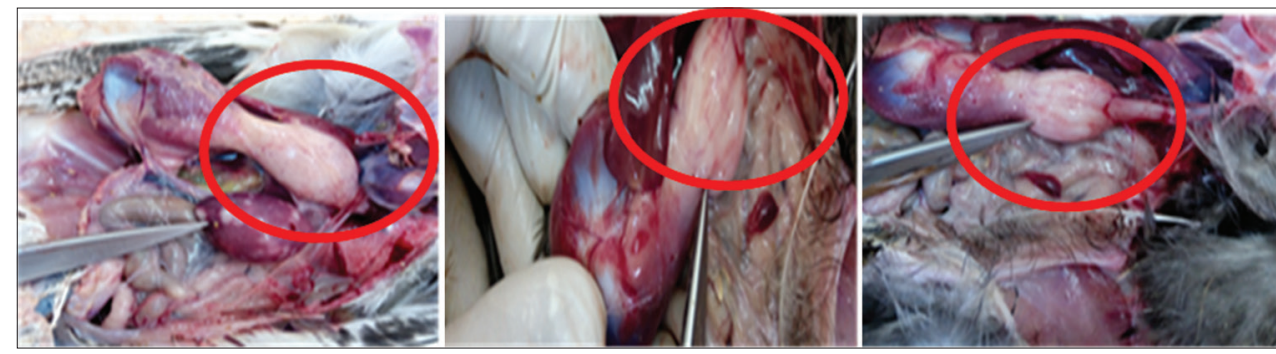

Fig. 10: The red rings showed malabsorption syndrome (characteristics to Reo disease) in proventriculus of unvaccinated chicken challenged with Reo virus

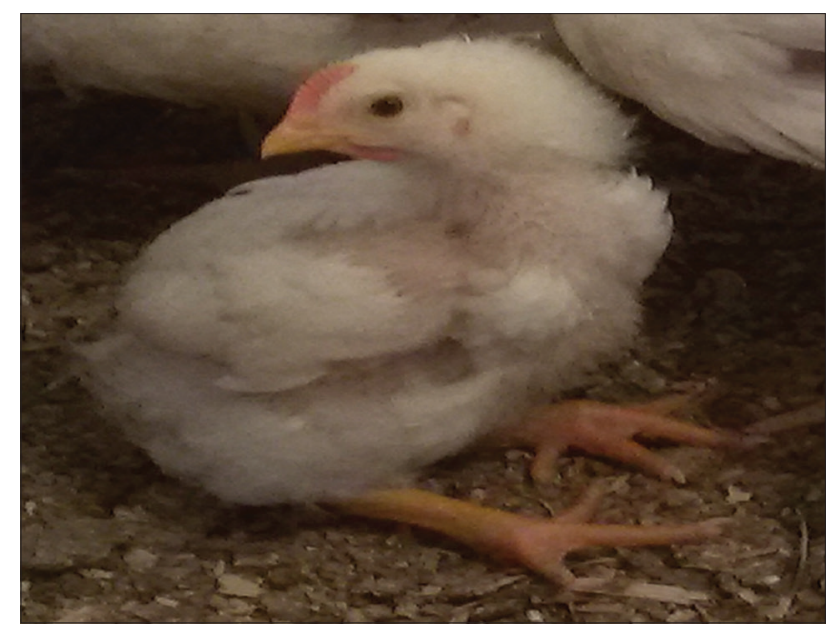

Fig. 11: Specific pathogen-free chicken show limpness associated with tenosynovitis in challenged unvaccinated group with Reo virus

Severity of clinical respiratory symptoms associated with MS, which exacerbated by co-infection with various respiratory viruses, such as ND and IB were reported Landman and Feberwee [9]. This is compatible with the present results, which revealed the highest titer of $\mathrm{ND}$ antibodies by HI test at the 28 days post-inoculation in Mycoplasma pre-infected group while the lowest titers were recorded in NDV inoculated alone.

The effect of MG on potency of IBV by was investigated by three ways (pre-, simultaneously- and post-vaccination). Inoculation the IB vaccine this following a part of the model of Landman and Feberwee [9], as clinical symptoms due to IBV were expected to peak. Hopkins and Yoder [29] suggested that chicken-passage mild IB vaccine virus markedly increased the incidence of airsacculitis compared with nonpassage vaccine virus so that chickens vaccinated with IB vaccine have higher $\mathrm{AB}$ titer and more protected against the IB disease alone. The effect of the previous infection of 8-week-old chicken with IBDV on their susceptibility to MS and Mycoplasma gallinaceum (MGn) then the antibody titers against MS and IBDV were detected by using HI and immune diffusion test [30]. Concomitant infection of MGn acts synergistically with MS and that previous exposure to IBDV increases the susceptibility of the synovial tissue to MS infection.

It was recorded that, birds infected with IBDV, that were later inoculated with MS (day 14), NDV (days 14 and 28), experienced an increased incidence and greater severity of airsacculitis than did chickens which were not exposed to IBDV [31]. Sarueng et al. [32] stated that severity of the respiratory disease resulting from infection by IBV is increased when there is co-infection with other infectious agents such as E. coli, MG and/or MS occurs. The present study recorded the protection percentage against IBDV revealing that all MG-infected IBD challenged groups showed higher protection percentage than the MG noninfected IBD challenged group. IBD has been shown to interfere with the serological response to MS [31]. Reproduced synovitis in chickens was in groups challenged with both IBDV and MS, but not with MS alone [30].

Many previous studies [33-35] help to support the overall importance of the present results. Reo viruses have been shown to interact with MS in the production of synovitis. This virus neutralizing antibodies were detected in group infected with Reo virus together with the Mycoplasma, at 3 weeks and persisted until the end of the experiment at 15 weeks. 


\section{CONCLUSION}

The aim of this study was trying to explain the adverse effect of Mycoplasma on the titration and potency of viral vaccines, and the results revealed that MG infection could lead to false evaluation of these vaccines. The interaction between Mycoplasmas and viruses has been considered to be important not only in natural infection but also in vaccination process failure.

\section{Compliance with ethics requirements}

Chickens care as well as experimental protocols were incompliance with guidelines of ethical standards released by CLEVB on animal care and use. All efforts were made to minimize the numbers of animals and their suffering in this study through following the guidelines on laboratory animal care and use.

\section{REFERENCES}

1. Kleven SH. Mycoplasmas in the etiology of multifactorial respiratory disease. Poult Sci 1998;77(8):1146-9.

2. Rottem S, Barile MF. Beware of mycoplasmas. Trends Biotechnol 1993;11(4):143-51.

3. Gaunson JE, Philip CJ, Whithear KG, Browning GF. Lymphocytic infiltration in the chicken trachea in response to Mycoplasma gallisepticum infection. Microbiology 2000;146(5):1223-9.3.

4. van Boven M, Bouma A, Fabri TH, Katsma E, Hartog L, Koch G. Herd immunity to Newcastle disease virus in poultry by vaccination. Avian Pathol 2008;37(1):1-5.

5. Spradbrow PB. Policy framework for smallholder rural poultry development. In: Proceedings of International Workshop on Sustainable Poultry Production in Africa Held in Addis Ababa, Ethiopia; 1997. p. 30-9.

6. Abd-Alla HI, Abu-Gabal NS, Hassan AZ, El-Safty MM, Shalaby NM. Antiviral activity of Aloe hijazensis against some haemagglutinating viruses infection and its phytoconstituents. Arch Pharm Res 2012;35(8):1347-54

7. Lakshmi R, Lavanya CR, Christymol B, Swathi KK. A study on antibiotic prescribing pattern in obstructive lung disease inpatients. Asian J Pharm Clin Res 2016;9(1):260-2.

8. Bradbury JM. Avian mycoplasma infections: Prototype of mixed infections with mycoplasmas, bacteria and viruses. Ann Microbiol (Paris) 1984:135A(1):83-9.

9. Landman WJ, Feberwee A. Aerosol-induced Mycoplasma synoviae arthritis: The synergistic effect of infectious bronchitis virus infection. Avian Pathol 2004;33(6):591-8.

10. Chen D, Wei Y, Huang L, Wang Y, Sun J, Du W, et al. Synergistic pathogenicity in sequential coinfection with Mycoplasma hyorhinis and porcine circovirus type 2. Vet Microbiol 2016;182:123-30.

11. Chu HP, Uppal PK. Single and mixed infections of avian infectious bronchitis virus and Mycoplasma gallisepticum. Dev Biol Stand 1975;28:101-14.

12. David SA, Volokhov DV, Ye Z, Chizhikov V. Evaluation of Mycoplasma inactivation during production of biologics: Egg-based viral vaccines as a model. Appl Environ Microbiol 2010;76(9):2718-28.

13. Bolha L, Bencina D, Cizelj I, Oven I, Slavec B, Rojs OZ, et al. Effect of Mycoplasma synoviae and lentogenic Newcastle disease virus coinfection on cytokine and chemokine gene expression in chicken embryos. Poult Sci 2013;92(12):3134-43

14. Naylor CJ, Al-Ankari AR, Al-Afaleq AI, Bradbury JM, Jones RC. Exacerbation of Mycoplasma gallisepticum infection in turkeys by rhinotracheitis virus. Avian Pathol 1992;21:295-305.

15. Rodwell AW, Whitcomb RF. Methods for direct and indirect measurement of Mycoplasma growth. In: Razin S, Tully JG, editors. Methods in Mycoplasmology. $1^{\text {st }}$ ed. New York, NY: Academic Press; 1983. p. 185-96.

16. Senne DA. Virus propagation in embryonating eggs. In: Swayne DE, Glisson JR, Jackwood MW, Pearson JE, Reed WM, editors.
A Laboratory Manual for the Isolation and Identification of Avian Pathogens. $4^{\text {th }}$ ed. Kennett Square, PA, USA: American Association of Avian Pathologists; 1998. p. 235-40.

17. Choi KS, Kye SJ, Jeon WJ, Park MJ, Kim S, Seul HJ, et al. Preparation and diagnostic utility of a hemagglutination inhibition test antigen derived from the baculovirus-expressed hemagglutinin-neuraminidase protein gene of Newcastle disease virus. J Vet Sci 2013;14(3):291-7.

18. Zaini MZ, Bradbury JM. Optimizing conditions for the isolation of Mycoplasma gallisepticum collected on applicator swabs. Vet Microbiol 1996;49(1-2):45-57.

19. Razin S, Tully JG, editors. Mycoplasma characteristic. In: Methods in Mycoplasmology. New York: Academic Press; 1983. p. 1.

20. Zute I, Valdovska A. Prevalence of Mycoplasma gallisepticum in the commercial layer flock. Res Rural Dev 2015;1:168-72.

21. OIE. Diseases Notifiable to the OIE: Animal Health World Organization; 2015. Available from: http://www.oie.int/eng/maladies/ en classification.

22. Office International Des Epizooties, (OIE). Manual of Standards for Diagnostic Tests and Vaccines. $4^{\text {th }}$ ed. Paris, France: OIE; 2002

23. Jordan FT, Yavari C, Knight D. Some observations on the indirect ELISA for antibodies to Mycoplasma iowae serovar in sera from turkeys considered to be free from Mycoplasma infections. Avian Pathol 1987; 16:307-18

24. Office of Government Information Services, Code of American Federal Regulations - National Archives and Records Administration (NARA), Biological Products: General Vol. 7, Part 600, Title 21. Published by the Office of the Federal Register National Archives and Records Administration as a Special Edition of the Federal Register, April 1, 2016.

25. Melnick JL. Health Sciences, Virology, Embryonated Egg Culture. Department of Virology and Epidemiology, Baylor College of Medicine, Houston, Texas. DOI: http://dx.doi.org/10.1036/1097-8542.230000.

26. Bolha L, Bencina D, Cizelj I, Oven I, Slavec B, Rojs OZ, et al. Effect of Mycoplasma synoviae and lentogenic Newcastle disease virus coinfection on cytokine and chemokine gene expression in chicken embryos. Poult Sci 2013;92(12):3134-43.

27. Lagier JC, Edouard S, Pagnier I, Mediannikov O, Drancourt M, Raoult D. Current and past strategies for bacterial culture in clinical microbiology. Clin Microbiol Rev 2015;28(1):208-36

28. Song Q, Xu BP, Shen KL. Effects of bacterial and viral co-infections of Mycoplasma pneumoniae pneumonia in children: Analysis report from Beijing Children's Hospital between 2010 and 2014. Int J Clin Exp Med 2015;8(1):15666-74.

29. Hopkins SR, Yoder HW Jr. Increased incidence of airsacculitis in broilers infected with Mycoplasma synoviae and chicken-passaged infectious bronchitis vaccine virus. Avian Dis 1984:28:386-96.

30. Yagihashi T, Nunoya T, Otaki Y. Effects of dual infection of chickens with Mycoplasma synoviae and Mycoplasma gallinaceum or infectious bursal disease virus on infectious synovitis. Jpn J Vet Sci 1983;45(4):529-32.

31. Giambrone JJ, Eidson CS, Kleven SH. Effect of infectious bursal disease on the response of chickens to Mycoplasma synoviae, Newcastle disease virus, and infectious bronchitis virus. Am J Vet Res 1977:38:251-3.

32. Sarueng E, Wanasawaeng W, Sasipreeyajan J, Chansiripornchai N. Efficacy of live infectious bronchitis vaccine programs against infection by QX-like strain of infectious bronchitis virus. Thai J Vet Med 2014;44:187-94.

33. Bradbury JM, Garuti A. Dual infection with Mycoplasma synoviae and a tenosynovitis-inducing reovirus in chickens. Avian Pathol 1978;7:407-19.

34. Alafaleq A, Bradbury JM, Jones RC, Metwali AM. Mixed infection of turkeys with Mycoplasma synoviae and reovirus: Field and experimental observations. Avian Pathol 1989;18:441-53.

35. Abu-Gabal NS, Abd-Alla HI, Mohamed NZ, Aly HF, Shalaby NM. Phenolics composition, hypolipidemic, hypoglycemic and antioxidative effects of the leaves of Fortunella japonica (Thunb.) Swingle. Int J Pharm Pharm Sci 2015;7(12):55-63. 